\title{
An Experimental Analysis on various states of Dry Cement with Chemical Compounds
}

\author{
Prof. Vaishali Sarangpure \\ Assistant Professor, Department of Computer Science and Engineering, \\ K.D.K. Women's College India \\ Vaishali.sarangpure@gmail.com
}

Abstract

Portland is pressure driven make by finely pounding the clinker created by calcining to early mix a blend of argillaceous and in like way calcareous supplies. It encounters a synthetic response with water units and sets when drawn in with air or besides submerged In this paper we are discussing two assorted methodology to make concrete that are wet system and dry strategy. Wet methodology minerals are wet ground by including water to shape a slurry and a short time later dried. Dry technique minerals are dry ground to shape a powder like substance.

Keywords: Compound, Dry cement, clinker etc.

\section{INTRODUCTION}

Portland concrete is a fine powder which is conveyed by warming limestone and dirt t minerals in an oven and structures clinker. The clinker is granulated to fine powder with development of unassuming amount of various materials. It is the most regularly used sorts of concrete on the planet. It is used as basic components of strong, mortar, mortar, etc. It is named as Portland concrete because of its equivalence to Portland stone which was found on the Isle of Portland in Dorset, England. It's an outrageous floor material having glue and strong properties, which give a coupling mode for discrete segments. It a general term uses to delineate water driven. The regular crude materials used for making concrete are limestone ( $\mathrm{CaCo} 3 \neg)$, sand (Sio2 ᄀ), state dirt (Sio2, Al2O3 or $\mathrm{Fe} 2 \neg \mathrm{O} 3 \neg$ ) and moreover iron oxide. Thusly, the concoction parts are calcium $(\mathrm{Ca})$, silicon $(\mathrm{Si})$, aluminum $(\mathrm{Al})$ and iron $(\mathrm{Fe})$. 


\section{PROCESS OF MANUFACTURE PORTLAND}

The creation procedure of silicate cement also called Portland cement that is delegate in cement creation. It receives limestone and clay as primary materials. After been squashed, proportioned and ground into suitable granularity, the vast majority of the raw materials will be taken care of into cement kiln for calcining clinker, and afterward we for the most part include a proper measure of gypsum in the cement grinding process, at last acquiring the cement items with a certified fineness. At cement plant, as indicated by various raw materials readiness techniques, cement assembling can be partitioned into the dry procedure and wet procedure

\section{The wet process for the manufacturing of Portland cement}

In the wet procedure, limestone is first squashed to littler pieces. At that point, it takes to ball or tube mills where it blends in with clay and finely ground. At that point, water adds to it to make a slurry. It pumps to slurry tanks, where it keep in a disturbed condition by methods for turning arm or by compressed air from the base to forestall settling of limestone and of the adaptable chain, loses moisture and becomes flakes. These flakes drop response happens and 20 to $30 \%$ of materials get the fuse. Lime, silica, and alumina get recombine the melded mass goes into to nodular structure called clinker. The clinker drops into the revolving cooler where it cool under controlled conditions. The cool clinker is then ground in a ball plant with the expansion of 2 to $3 \%$ of gypsum.

\section{Advantages}

The wet procedure of cement creation has the qualities of straightforward activity, low residue and simple passing on. Since the slurry has ease with the goal that its homogeneity is acceptable and the nature of clinker is improved. In addition, the vitality utilization of raw material granulating in the wet procedure is decreased by almost $30 \%$. 


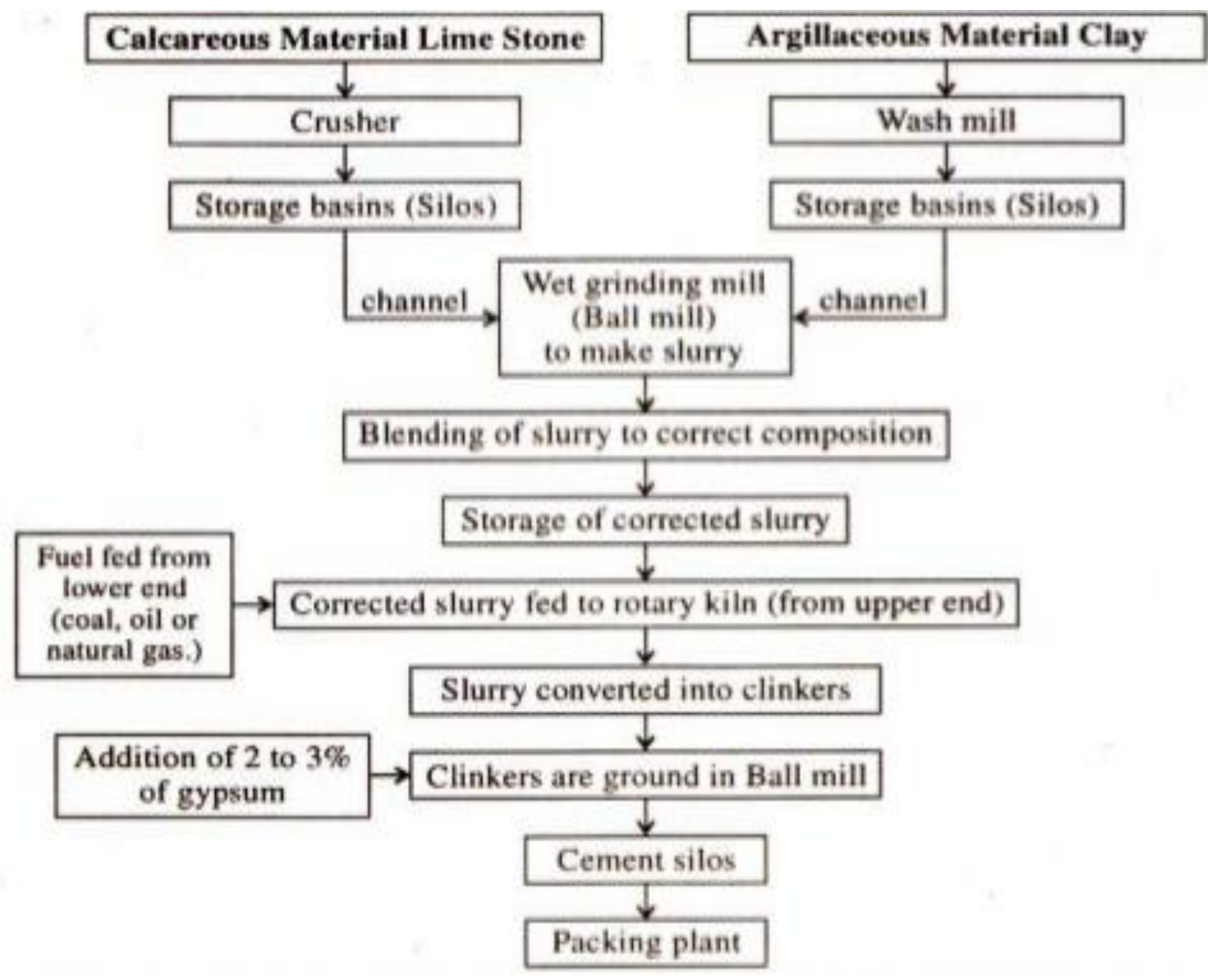

Fig 1: The wet process for the manufacturing of Portland cement

\section{The dry procedure for the manufacturing of Portland cement}

In this procedure, the raw materials dried and ground to a fine powder by grinding mill. The dry powder is then further blende and rectified for its correct composition and blended by methods for compressed air. The mixed powder at that point store in the capacity storehouses from where. It is the go to the granulator involving a inclined rotating drum or dish. An amount of water around 12 percent by weight at that point adds to make the mixed powder into nodules. These nodules are then dry by preheater and afterward enter to the rotational oven from the upper end. These knobs drop to bring down end where it subject to the temperature about 1500 oc Chemical response happens and 20 to $30 \%$ material gets the fuse. Lime silica and alumina get recombine. The melded mass transforms into a nodular structure called clinker. The clinker drops into the rotating cooler, where it is cool leveled out conditions. The cool clinker is then ground in a ball plant with the expansion of 2 to $3 \%$ of gypsum. In the ball plant, particles pound to a fine powder 
and filled into packs. The hardware utilized in the dry procedure in similarly littler. This procedure is affordable than the wet procedure. The all out utilization of coal in the dry procedure is just around $100 \mathrm{~kg}$, when contrasted with the necessity of around $350 \mathrm{~kg}$, for delivering a huge amount of cement in the wet procedure.

Advantages: as the dry procedure is to straightforwardly take care of raw material powder into the rotational kiln for calcination, and the dampness substance of raw materials is about $1 \%-$ $2 \%$, it saves the heat utilization required for the moisture dissipation. Thusly, this technique has the benefits of vitality sparing, high creation productivity and stable yield, which can meet the creation needs of enormous cement plants. Simultaneously, there is less sewage released in the dry procedure cement creation. It is helpful for ecological insurance. These days, we call the creation line with preheater and proclaimer as the new dry procedure cement creation line, which is the advancement direction of dry procedure cement manufacturing in the future.

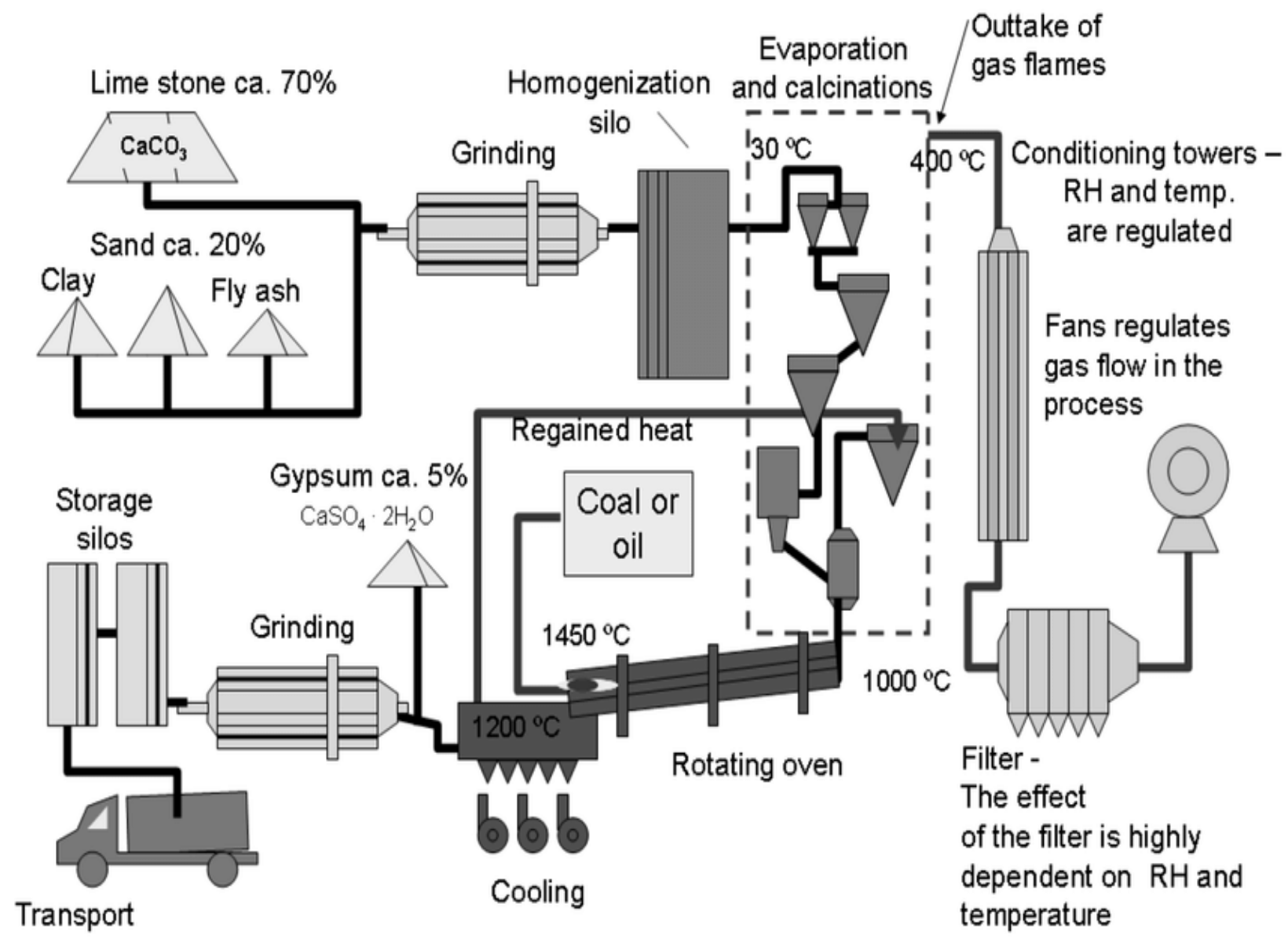

Fig 2: The dry procedure for the manufacturing of Portland cement 
Table 1:

Portland cement chemical composition limits

\begin{tabular}{|l|l|c|c|}
\hline Common Name & \multicolumn{1}{|c|}{ Oxide } & Abbreviation & $\begin{array}{c}\text { Appropriate } \\
\text { Composition Limits (in } \\
\% \text { ) }\end{array}$ \\
\hline Lime & $\mathrm{CaO}$ & $\mathrm{C}$ & $60-66$ \\
\hline Silica & $\mathrm{SiO} 2$ & $\mathrm{~S}$ & $19-25$ \\
\hline Alumina & $\mathrm{A} 12 \mathrm{O} 3$ & $\mathrm{~A}$ & $3-8$ \\
\hline Iron oxide & $\mathrm{Fe} 2 \mathrm{O} 3$ & $\mathrm{~F}$ & $1-5$ \\
\hline Magnesia & $\mathrm{MgO}$ & $\mathrm{M}$ & $0-5$ \\
\hline Alkalies & & & $0.5-1$ \\
\hline Soda & $\mathrm{Na} 2 \mathrm{O}$ & $\mathrm{N}$ & $0.5-1$ \\
\hline Potassa & $\mathrm{K} 2 \mathrm{O}$ & $\mathrm{K}$ & $1-3$ \\
\hline Sulfur Trioxide & $\mathrm{SO} 3$ & $\overline{\mathrm{S}}$ & \\
\hline
\end{tabular}

\section{CONCLUSION}

It alludes to inorganic pressure driven concretes which are hydration structure respectably insoluble water strengthened total of high caliber and dimensional security. The Wet Process is the first is being evacuated by Dry Process for barely any assembling plants because of sparing vitality, exact control and suitable blending of the crude material. The dry technique plants speak to $58 \%$ of the total aggregate made with full creation limit.

\section{REFERENCES}

[1] S. Sinthaworn and P. Nimityongskul, "Quick monitoring of pozzolanic reactivity of waste ashes," Waste Management, vol.29, no. 5, pp. 1526-1531, 2009.

[2] J. J. Brooks,M. A.M. Johari, andM.Mazloom, "Effect of admixtures on the setting times of highstrength concrete," Cement and Concrete Composites, vol. 22, no. 4, pp. 293-301, 2000.

[3] X. Fu, Z.Wang,W. Tao et al., "Studies on blended cement with a large amount of fly ash," Cement and Concrete Research, vol. 32,no. 7, pp. 1153-1159, 2002.

[4] E.-H. Kadri, S. Kenai, K. Ezziane, R. Siddique, and G. De Schutter, "Influence of metakaolin and silica fume on the heat of hydration and compressive strength development of mortar," Applied Clay Science, vol. 53, no. 4, pp. 704-708, 2011.

[5] V. Indrawati and A. Manaf, "Mechanical strength of trass as supplementary cementing material," Journal of Physical Science, vol. 92, no. 2, pp. 51-59, 2008.

[6] D. N. Huntzinger and T. D. Eatmon, "A life-cycle assessment of Portland cement manufacturing: comparing the traditional process with alternative technologies," Journal of Cleaner Production, vol. 17 , no. 7, pp. 668-675, 2009.

[7] F. M. Lea, The Chemistry of Cement and Concrete, Arnold Publishers, London, UK, 3rd edition, 1970. 
[8] J. F. Young, S.Mindess, R. J. Gray, andA. Bentur,TheScience andTechnology of Civil Engineering Materials, Prentice-Hall, Upper Saddle River, NJ, USA, 1998.

[9] H. F. W. Taylor, Cement Chemistry, Thomas Telford, London,UK, 2nd edition, 1997.

[10] S. H. Kosmatka and M. L. Wilson, Design and Control of Concrete Mixtures, Portland Cement Association, Stokie, Ill, USA, 2011.

[11] V. Sata, C. Jaturapitakkul, and K. Kiattikomol, "Influence of pozzolan from various by-product materials on mechanical properties of high-strength concrete," Construction and BuildingMaterials, vol. 21, no. 7, pp. 1589-1598, 2007.

[12] A. Neville, Neville on Concrete, ACI, Farmington Hills, Mich, USA, 2003.

[13] R. Fernandez, F. Martirena, and K. L. Scrivener, "The origin of the pozzolanic activity of calcined clay minerals: a comparison between kaolinite, illite and montmorillonite," Cement and

Concrete Research, vol. 41, no. 1, pp. 113-122, 2011.

[14] K. Ganesan, K. Rajagopal, and K. Thangavel, "Evaluation of bagasse ash as supplementary cementitious material," Cement and Concrete Composites, vol. 29, no. 6, pp. 515-524, 2007. 